Int. J. Mol. Sci. 2010, 11, 3357-3374; doi:10.3390/ijms11093357

OPEN ACCESS

International Journal of

Molecular Sciences

ISSN 1422-0067

www.mdpi.com/journal/ijms

Article

\title{
3D-QSAR and Molecular Docking Studies on Fused Pyrazoles as p38a Mitogen-Activated Protein Kinase Inhibitors
}

\author{
Ping Lan, Zhi-Jian Huang, Jun-Rong Sun and Wei-Min Chen * \\ Guangdong Province Key Laboratory of Pharmacodynamic Constituents of TCM and New Drugs \\ Research, College of Pharmacy, Jinan University ,Guangzhou 510632, Guangdong, China; \\ E-Mails: lanpingsmzh@126.com (P.L.); huangzhijian0505@gmail.com (Z.-J.H.); \\ sunjunrong1986@yahoo.com.cn (J.-R.S.) \\ * Author to whom correspondence should be addressed; E-Mail: twmchen @ jnu.edu.cn; \\ Tel. +86-20-852-244-97; Fax: +86-20-852-247-66.
}

Received: 6 July 2010 / Accepted: 3 September 2010 / Published: 17 September 2010

\begin{abstract}
The p38 $\alpha$ mitogen-activated protein kinase (MAPK) has become an attractive target for the treatment of many diseases such as rheumatoid arthritis, inflammatory bowel disease and Crohn's disease. In this paper, 3D-QSAR and molecular docking studies were performed on 59 p38 $\alpha$ MAPK inhibitors. Comparative molecular field analysis (CoMFA) and comparative molecular similarity indices analysis (CoMSIA) were applied to determine the structural requirements for potency in inhibiting p38 $\alpha$ MAPK. The resulting model of CoMFA and CoMSIA exhibited good $r_{\mathrm{cv}}^{2}$ values of 0.725 and 0.609 , and $r^{2}$ values of 0.961 and 0.905 , respectively. Molecular docking was used to explore the binding mode between the inhibitors and p38 $\alpha$ MAPK. We have accordingly designed a series of novel p38 $\alpha$ MAPK inhibitors by utilizing the structure-activity relationship (SAR) results revealed in the present study, which were predicted with excellent potencies in the developed models. The results provided a useful guide to design new compounds for $\mathrm{p} 38 \alpha$ MAPK inhibitors.
\end{abstract}

Keywords: p38 $\alpha$ mitogen-activated protein kinase; 3D-QSAR; CoMFA; CoMSIA; docking

\section{Introduction}

The p38 mitogen-activated protein kinase (MAPK), a serine/threonine kinase, plays a crucial role in biosynthesis of pro-inflammatory cytokines including tumor necrosis factor $\alpha$ (TNF $\alpha$ ) and 
interleukin-1 $\beta$ (IL-1 $\beta$ ) [1]. The p38 MAPK exists in four isoforms $(\alpha, \beta, \gamma$ and $\delta)$. Expression of these isoforms varies across cell types of the immune system, and it was revealed by previous studies that the predominant isoform involved in inflammation is $\mathrm{p} 38 \alpha[2,3]$. The p38 $\alpha$ MAPK is activated by a range of environmental stimuli such as TNF $\alpha$, IL- $1 \beta$ and stress. Activation of $\mathrm{p} 38 \alpha$ leads to the up-regulation of both TNF $\alpha$ and IL-1 $\beta$, resulting in many chronic inflammatory diseases, such as rheumatoid arthritis (RA), inflammatory bowel disease, Crohn's disease, and chronic obstructive pulmonary disease (COPD), as well as the other inflammatory disorders [4-8].

The proven ability of p38 MAPK to efficiently regulate both the release and the activity of these pro-inflammatory cytokines has prompted many pharmaceutical groups to pursue inhibitors of p38 MAPK for the potential treatment of various inflammatory diseases [9-11]. A series of fused pyrazole derivatives with potent, selective and orally available inhibition activities towards p38 MAPK were reported [1-3]. In this paper, 3D-QSAR and molecular docking studies were performed on these inhibitors. Along with the molecular docking, 3D-QSAR approaches including comparative molecular field analysis (CoMFA) and comparative molecular similarity analysis (CoMSIA) could offer more insight into understanding the structure-activity relationship of these inhibitors, and thus could more effectively direct the design of new potential inhibitors. Based on the structure-activity relationship revealed in the present study, a series of novel p38 $\alpha$ MAPK inhibitors were accordingly designed.

\section{Materials and Methods}

\subsection{Dataset for Analysis}

All the compounds and associated biological activities were selected from literature [1-3] reported by the same research group. These fused pyrazole derivatives were divided into a training set of 46 compounds and a test set of 13 compounds. The inhibitory data was reported as $\mathrm{IC}_{50}$ towards $\mathrm{p} 38 \alpha$ MAPK, and the $\mathrm{IC}_{50}$ values were converted into corresponding $\mathrm{pIC}_{50}$ by taking $\mathrm{Log}\left(1 / \mathrm{IC}_{50}\right)$. The $\mathrm{pIC}_{50}$ values were used as the dependent variables in all the models subsequently developed. Structures and associated inhibitory activities are shown in Tables 1 and 2.

Table 1. The chemical structures of the fused pyrazole derivatives used for the training and test set.

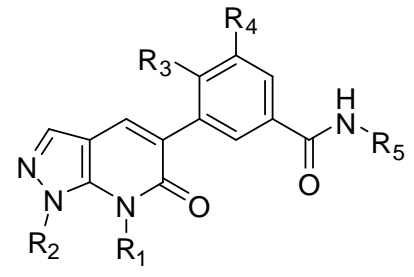

1-12

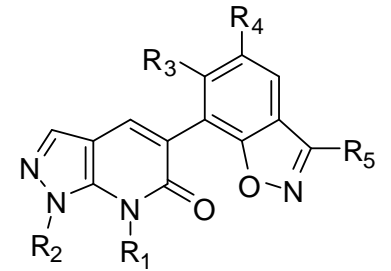

13

\begin{tabular}{cccccc}
\hline Compound & \multicolumn{5}{c}{ Substituent } \\
\cline { 2 - 6 } No. & $\mathbf{R}_{\mathbf{1}}$ & $\mathbf{R}_{\mathbf{2}}$ & $\mathbf{R}_{\mathbf{3}}$ & $\mathbf{R}_{\mathbf{4}}$ & $\mathbf{R}_{\mathbf{5}}$ \\
\hline $\mathbf{1}$ & $\mathrm{Me}$ & $2-\mathrm{Me}-\mathrm{Ph}$ & $\mathrm{Me}$ & $\mathrm{H}$ & Cyclopropyl \\
$\mathbf{2}$ & $\mathrm{Me}$ & $2-\mathrm{Cl}-\mathrm{Ph}$ & $\mathrm{Me}$ & $\mathrm{H}$ & Cyclopropyl \\
& $\mathrm{Me}$ & & $\mathrm{Me}$ & $\mathrm{H}$ & Cyclopropyl \\
\hline
\end{tabular}


Table 1. Cont.

\begin{tabular}{|c|c|c|c|c|c|}
\hline \multirow{2}{*}{$\begin{array}{c}\text { Compound } \\
\text { No. }\end{array}$} & \multicolumn{5}{|c|}{ Substituent } \\
\hline & $\mathbf{R}_{1}$ & $\mathbf{R}_{2}$ & $\mathbf{R}_{\mathbf{3}}$ & $\mathbf{R}_{\mathbf{4}}$ & $\mathbf{R}_{5}$ \\
\hline 4 & $\mathrm{Me}$ & 2,4-Di-F-Ph & $\mathrm{Me}$ & $\mathrm{H}$ & Cyclopropyl \\
\hline 5 & $\mathrm{Me}$ & 2,5-Di-F-Ph & $\mathrm{Me}$ & $\mathrm{H}$ & Cyclopropyl \\
\hline 6 & $\mathrm{Me}$ & 2,6-Di-F-Ph & $\mathrm{Me}$ & $\mathrm{H}$ & Cyclopropyl \\
\hline 7 & Et & 2,4-Di-F-Ph & $\mathrm{Me}$ & $\mathrm{H}$ & Cyclopropyl \\
\hline 8 & $\mathrm{Me}$ & 2,6-Di-F-Ph & $\mathrm{Cl}$ & $\mathrm{H}$ & Cyclopropyl \\
\hline 9 & $\mathrm{Me}$ & 2,6-Di-F-Ph & $\mathrm{Me}$ & $\mathrm{F}$ & Cyclopropyl \\
\hline 10 & $\mathrm{Me}$ & 2,6-Di-F-Ph & $\mathrm{Me}$ & $\mathrm{H}$ & $\mathrm{H}$ \\
\hline 11 & $\mathrm{Me}$ & 2,6-Di-F-Ph & $\mathrm{Me}$ & $\mathrm{H}$ & \\
\hline 12 & $\mathrm{Me}$ & 2,6-Di-F-Ph & $\mathrm{Me}$ & $\mathrm{H}$ & \\
\hline 13 & $\mathrm{Me}$ & 2,6-Di-F-Ph & $\mathrm{Me}$ & $\mathrm{H}$ & Methylamino \\
\hline & & & & & \\
\hline
\end{tabular}

14-17

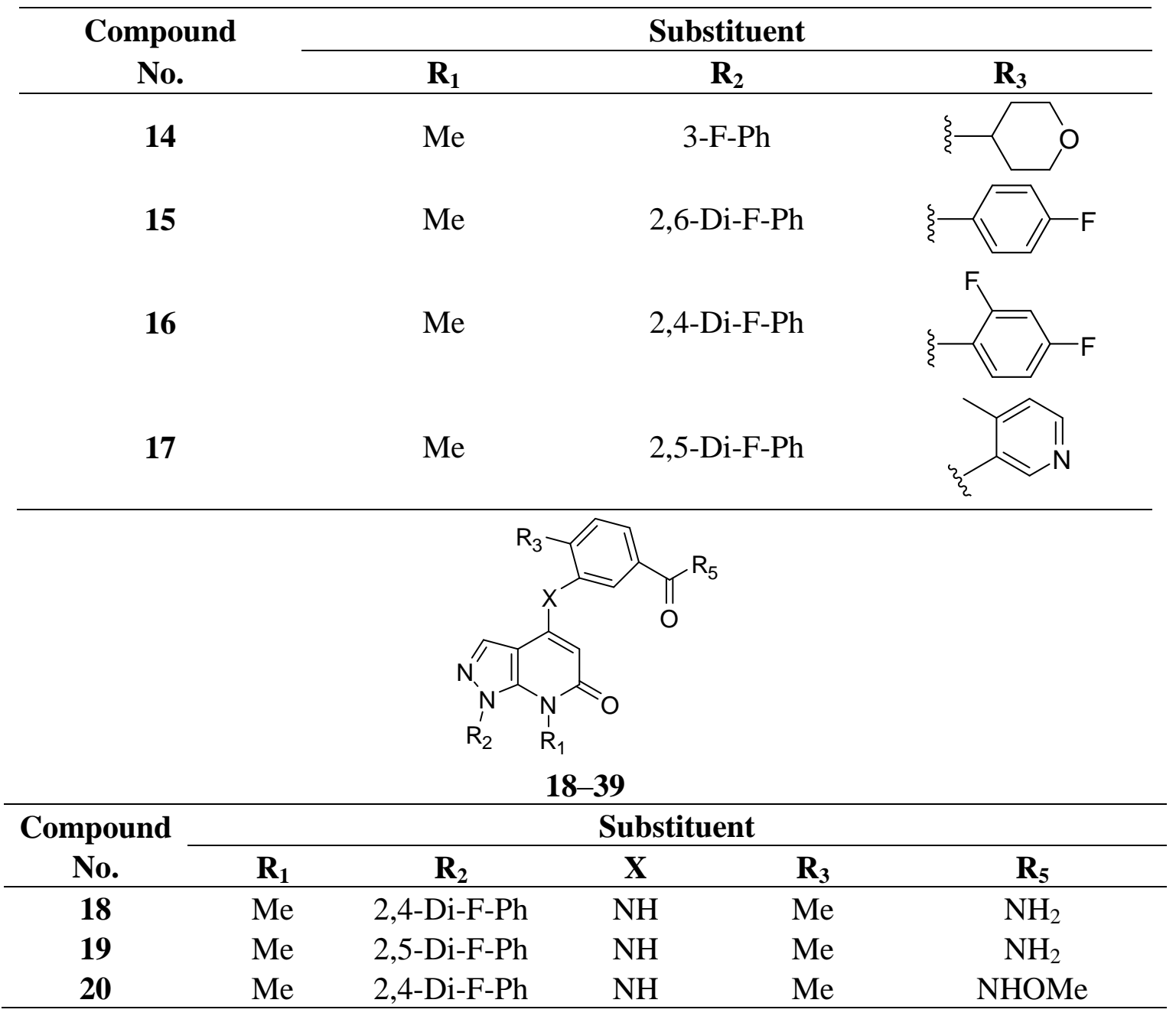


Table 1. Cont.

\begin{tabular}{|c|c|c|c|c|c|}
\hline \multirow{2}{*}{$\begin{array}{c}\text { Compound } \\
\text { No. }\end{array}$} & \multicolumn{5}{|c|}{ Substituent } \\
\hline & $\mathbf{R}_{1}$ & $\mathbf{R}_{2}$ & $\mathbf{X}$ & $\mathbf{R}_{\mathbf{3}}$ & $\mathbf{R}_{5}$ \\
\hline 21 & $\mathrm{Me}$ & 2,4-Di-F-Ph & $\mathrm{NH}$ & $\mathrm{Me}$ & Cyclopropylamino \\
\hline 22 & $\mathrm{Me}$ & 2,4-Di-F-Ph & $\mathrm{NH}$ & $\mathrm{Me}$ & t-butylamino \\
\hline 23 & $\mathrm{Me}$ & 2,4-Di-F-Ph & $\mathrm{NH}$ & $\mathrm{Me}$ & $\mathrm{OH}$ \\
\hline 24 & $\mathrm{Me}$ & 3-F-Ph & $\mathrm{NH}$ & $\mathrm{Me}$ & Cyclopropylamino \\
\hline 25 & $\mathrm{Me}$ & 3-F-Ph & $\mathrm{O}$ & $\mathrm{Me}$ & Cyclopropylamino \\
\hline 26 & $\mathrm{Me}$ & 4-F-Ph & $\mathrm{NH}$ & $\mathrm{Cl}$ & Cyclopropylamino \\
\hline 27 & $\mathrm{Et}$ & 4-F-Ph & $\mathrm{NH}$ & $\mathrm{Me}$ & Cyclopropylamino \\
\hline 28 & Et & 4-F-Ph & $\mathrm{NH}$ & $\mathrm{Cl}$ & Cyclopropylamino \\
\hline 29 & Et & 4-F-Ph & $\mathrm{O}$ & $\mathrm{Me}$ & Cyclopropylamino \\
\hline 30 & $\mathrm{Et}$ & 2,4-Di-F-Ph & $\mathrm{NH}$ & $\mathrm{Cl}$ & Cyclopropylamino \\
\hline 31 & $\mathrm{Me}$ & 2,4-Di-F-Ph & $\mathrm{O}$ & $\mathrm{Me}$ & Cyclopropylamino \\
\hline 32 & $\mathrm{Me}$ & 2,5-Di-F-Ph & $\mathrm{NH}$ & $\mathrm{Me}$ & Cyclopropylamino \\
\hline 33 & $\mathrm{Me}$ & 2,5-Di-F-Ph & $\mathrm{NH}$ & $\mathrm{Cl}$ & Cyclopropylamino \\
\hline 34 & $\mathrm{Me}$ & 2,5-Di-F-Ph & $\mathrm{O}$ & $\mathrm{Me}$ & Cyclopropylamino \\
\hline 35 & $\mathrm{Me}$ & 2,5-Di-F-Ph & $\mathrm{O}$ & $\mathrm{Cl}$ & Cyclopropylamino \\
\hline 36 & $\mathrm{Me}$ & 2,6-Di-F-Ph & $\mathrm{NH}$ & $\mathrm{Me}$ & Cyclopropylamino \\
\hline 37 & $\mathrm{Me}$ & 2,6-Di-F-Ph & $\mathrm{NH}$ & $\mathrm{Cl}$ & Cyclopropylamino \\
\hline 38 & $\mathrm{Me}$ & 2,6-Di-F-Ph & $\mathrm{NH}$ & $\mathrm{F}$ & Cyclopropylamino \\
\hline 39 & $\mathrm{Me}$ & 2,6-Di-F-Ph & $\mathrm{O}$ & $\mathrm{Me}$ & Cyclopropylamino \\
\hline
\end{tabular}

40-59

\begin{tabular}{cccccc}
\hline Compound & \multicolumn{5}{c}{ Substituent } \\
\cline { 2 - 6 } No. & $\mathbf{R}_{\mathbf{1}}$ & $\mathbf{R}_{\mathbf{2}}$ & $\mathbf{X}$ & $\mathbf{R}_{\mathbf{3}}$ & $\mathbf{R}_{\mathbf{4}}$ \\
\hline $\mathbf{4 0}$ & $\mathrm{H}$ & $2-\mathrm{Cl}-\mathrm{Ph}$ & $\mathrm{NH}$ & $\mathrm{Cl}$ & $\mathrm{H}$ \\
$\mathbf{4 1}$ & $\mathrm{H}$ & $3-\mathrm{F}-\mathrm{Ph}$ & $\mathrm{NH}$ & $\mathrm{Me}$ & $\mathrm{H}$ \\
$\mathbf{4 2}$ & $\mathrm{H}$ & $3-\mathrm{F}-\mathrm{Ph}$ & $\mathrm{NH}$ & $\mathrm{Cl}$ & $\mathrm{H}$ \\
$\mathbf{4 3}$ & $\mathrm{H}$ & $4-\mathrm{F}-\mathrm{Ph}$ & $\mathrm{NH}$ & $\mathrm{Cl}$ & $\mathrm{H}$ \\
$\mathbf{4 4}$ & $\mathrm{H}$ & $2,4-\mathrm{Di}-\mathrm{F}-\mathrm{Ph}$ & $\mathrm{NH}$ & $\mathrm{Me}$ & $\mathrm{H}$ \\
$\mathbf{4 5}$ & $\mathrm{H}$ & $2,4-\mathrm{Di}-\mathrm{F}-\mathrm{Ph}$ & $\mathrm{NH}$ & $\mathrm{Cl}$ & $\mathrm{H}$ \\
$\mathbf{4 6}$ & $\mathrm{H}$ & $2,4-\mathrm{Di}-\mathrm{F}-\mathrm{Ph}$ & $\mathrm{O}$ & $\mathrm{Me}$ & $\mathrm{H}$ \\
$\mathbf{4 7}$ & $\mathrm{H}$ & $2,4-\mathrm{Di}-\mathrm{F}-\mathrm{Ph}$ & $\mathrm{O}$ & $\mathrm{Cl}$ & $\mathrm{H}$ \\
$\mathbf{4 8}$ & $\mathrm{H}$ & $2,5-\mathrm{Di}-\mathrm{F}-\mathrm{Ph}$ & $\mathrm{NH}$ & $\mathrm{Cl}$ & $\mathrm{H}$ \\
$\mathbf{4 9}$ & $\mathrm{H}$ & $2,6-\mathrm{Di}-\mathrm{F}-\mathrm{Ph}$ & $\mathrm{NH}$ & $\mathrm{Me}$ & $\mathrm{H}$ \\
$\mathbf{5 0}$ & $\mathrm{H}$ & $2,6-\mathrm{Di}-\mathrm{F}-\mathrm{Ph}$ & $\mathrm{NH}$ & $\mathrm{Cl}$ & $\mathrm{H}$ \\
$\mathbf{5 1}$ & $\mathrm{H}$ & $2,6-\mathrm{Di}-\mathrm{F}-\mathrm{Ph}$ & $\mathrm{O}$ & $\mathrm{Me}$ & $\mathrm{H}$ \\
$\mathbf{5 2}$ & $\mathrm{Me}$ & $4-\mathrm{F}-\mathrm{Ph}$ & $\mathrm{NH}$ & $\mathrm{Me}$ & $\mathrm{H}$ \\
$\mathbf{5 3}$ & $\mathrm{Me}$ & $4-\mathrm{F}-\mathrm{Ph}$ & $\mathrm{NH}$ & $\mathrm{Cl}$ & $\mathrm{H}$ \\
\hline
\end{tabular}


Table 1. Cont.

\begin{tabular}{cccccc}
\hline Compound & \multicolumn{5}{c}{ Substituent } \\
\cline { 2 - 6 } No. & $\mathbf{R}_{\mathbf{1}}$ & $\mathbf{R}_{\mathbf{2}}$ & $\mathbf{X}$ & $\mathbf{R}_{\mathbf{3}}$ & $\mathbf{R}_{\mathbf{4}}$ \\
\hline $\mathbf{5 4}$ & $\mathrm{Me}$ & $4-\mathrm{F}-\mathrm{Ph}$ & $\mathrm{O}$ & $\mathrm{Me}$ & $\mathrm{H}$ \\
$\mathbf{5 5}$ & $\mathrm{Me}$ & $2,4-\mathrm{Di}-\mathrm{F}-\mathrm{Ph}$ & $\mathrm{NH}$ & $\mathrm{Me}$ & $\mathrm{H}$ \\
$\mathbf{5 6}$ & $\mathrm{Me}$ & $2,4-\mathrm{Di}-\mathrm{F}-\mathrm{Ph}$ & $\mathrm{NH}$ & $\mathrm{Me}$ & $\mathrm{F}$ \\
$\mathbf{5 7}$ & $\mathrm{Me}$ & $2,4-\mathrm{Di}-\mathrm{F}-\mathrm{Ph}$ & $\mathrm{NH}$ & $\mathrm{Cl}$ & $\mathrm{H}$ \\
$\mathbf{5 8}$ & $\mathrm{Me}$ & $2,4-\mathrm{Di}-\mathrm{F}-\mathrm{Ph}$ & $\mathrm{O}$ & $\mathrm{Me}$ & $\mathrm{H}$ \\
$\mathbf{5 9}$ & $\mathrm{Me}$ & $2,6-\mathrm{Di}-\mathrm{F}-\mathrm{Ph}$ & $\mathrm{NH}$ & $\mathrm{Cl}$ & $\mathrm{H}$ \\
\hline
\end{tabular}

Table 2. The experimental $\mathrm{pIC}_{50}$ values, predicted $\mathrm{pIC}_{50}$ values (Pred.) and their residuals (Res.) of the pyrazole derivative training and test set molecules.

\begin{tabular}{|c|c|c|c|c|c|}
\hline \multirow{2}{*}{$\begin{array}{c}\text { Compd. } \\
\text { No. }\end{array}$} & \multirow{2}{*}{ Experimental } & \multicolumn{2}{|c|}{ CoMFA } & \multicolumn{2}{|c|}{ CoMSIA } \\
\hline & & Pred. & Res. & Pred. & Res. \\
\hline 1 & 8.721 & 8.777 & -0.056 & 8.957 & -0.236 \\
\hline $2 *$ & 9.046 & 8.778 & 0.268 & 8.905 & 0.141 \\
\hline 3 & 8.638 & 8.682 & -0.044 & 8.764 & -0.126 \\
\hline $4 *$ & 8.638 & 8.572 & 0.066 & 8.858 & -0.220 \\
\hline 5 & 8.721 & 8.639 & 0.082 & 8.790 & -0.069 \\
\hline 6 & 8.854 & 8.995 & -0.141 & 8.879 & -0.025 \\
\hline 7 & 9.222 & 8.929 & 0.293 & 8.920 & 0.302 \\
\hline 8 & 8.959 & 9.010 & -0.051 & 8.841 & 0.118 \\
\hline 9 & 9.097 & 9.111 & -0.014 & 8.972 & 0.125 \\
\hline $10 *$ & 8.824 & 9.006 & -0.182 & 8.873 & -0.049 \\
\hline 11 & 8.770 & 8.972 & -0.202 & 8.903 & -0.133 \\
\hline 12 & 9.000 & 8.839 & 0.161 & 8.868 & 0.132 \\
\hline 13 & 8.699 & 8.742 & -0.043 & 8.826 & -0.127 \\
\hline 14 & 6.000 & 6.004 & -0.004 & 5.830 & 0.170 \\
\hline 15 & 6.000 & 6.067 & -0.067 & 6.266 & -0.266 \\
\hline $16^{*}$ & 6.000 & 5.862 & 0.138 & 6.340 & -0.340 \\
\hline 17 & 6.353 & 6.362 & -0.009 & 6.273 & 0.080 \\
\hline 18 & 8.585 & 8.533 & 0.052 & 8.637 & -0.052 \\
\hline $19 *$ & 8.432 & 8.568 & -0.136 & 8.566 & -0.134 \\
\hline 20 & 8.959 & 9.046 & -0.087 & 9.152 & -0.193 \\
\hline 21 & 8.495 & 8.396 & 0.099 & 7.804 & 0.691 \\
\hline 22 & 6.570 & 6.573 & -0.003 & 6.795 & -0.225 \\
\hline 23 & 6.000 & 5.986 & 0.014 & 6.047 & -0.047 \\
\hline 24 & 8.482 & 8.521 & -0.040 & 8.435 & 0.047 \\
\hline 25 & 8.071 & 8.248 & -0.177 & 8.566 & -0.495 \\
\hline 26 & 8.824 & 8.695 & 0.129 & 8.728 & 0.096 \\
\hline $27 *$ & 8.398 & 8.617 & -0.219 & 8.565 & -0.167 \\
\hline 28 & 8.921 & 8.985 & -0.064 & 8.840 & 0.081 \\
\hline 29 & 8.398 & 8.533 & -0.135 & 8.608 & -0.210 \\
\hline 30 & 8.959 & 9.075 & -0.116 & 8.800 & 0.159 \\
\hline 31 & 8.108 & 8.106 & 0.002 & 8.519 & -0.411 \\
\hline $32 *$ & 8.538 & 8.362 & 0.176 & 8.617 & -0.079 \\
\hline
\end{tabular}


Table 2. Cont.

\begin{tabular}{|c|c|c|c|c|c|}
\hline \multirow{2}{*}{$\begin{array}{c}\text { Compd. } \\
\text { No. }\end{array}$} & \multirow{2}{*}{ Experimental } & \multicolumn{2}{|c|}{ CoMFA } & \multicolumn{2}{|c|}{ CoMSIA } \\
\hline & & Pred. & Res. & Pred. & Res. \\
\hline 33 & 8.959 & 8.696 & 0.263 & 8.676 & 0.283 \\
\hline $34 *$ & 8.215 & 8.192 & 0.023 & 8.449 & -0.234 \\
\hline 35 & 8.482 & 8.504 & -0.022 & 8.732 & -0.250 \\
\hline 36 & 8.721 & 8.606 & 0.115 & 8.674 & 0.047 \\
\hline 37 & 8.959 & 8.939 & 0.020 & 8.735 & 0.224 \\
\hline 38 & 8.721 & 8.996 & -0.275 & 8.744 & -0.023 \\
\hline 39 & 8.854 & 8.546 & 0.308 & 8.543 & 0.311 \\
\hline 40 & 8.796 & 8.622 & 0.174 & 8.529 & 0.267 \\
\hline $41 *$ & 8.337 & 8.287 & 0.050 & 8.220 & 0.117 \\
\hline $42 *$ & 8.301 & 8.519 & -0.218 & 8.450 & -0.149 \\
\hline 43 & 8.071 & 8.410 & -0.339 & 8.459 & -0.388 \\
\hline 44 & 7.921 & 8.132 & -0.211 & 8.232 & -0.311 \\
\hline 45 & 8.482 & 8.419 & 0.063 & 8.463 & 0.019 \\
\hline 46 & 8.000 & 7.795 & 0.205 & 7.956 & 0.044 \\
\hline 47 & 7.444 & 7.754 & -0.310 & 7.946 & -0.502 \\
\hline 48 & 8.678 & 8.714 & -0.036 & 8.588 & 0.090 \\
\hline 49 & 8.770 & 8.761 & 0.009 & 8.680 & 0.090 \\
\hline $50 *$ & 8.854 & 8.887 & -0.033 & 8.635 & 0.219 \\
\hline 51 & 8.523 & 8.612 & -0.089 & 8.140 & 0.383 \\
\hline 52 & 8.387 & 8.182 & 0.205 & 8.225 & 0.162 \\
\hline 53 & 8.638 & 8.409 & 0.229 & 8.457 & 0.181 \\
\hline 54 & 8.114 & 7.849 & 0.265 & 7.968 & 0.146 \\
\hline $55^{*}$ & 8.569 & 8.513 & 0.056 & 8.649 & -0.080 \\
\hline 56 & 8.000 & 8.387 & -0.387 & 8.627 & -0.627 \\
\hline 57 & 8.796 & 8.648 & 0.148 & 8.605 & 0.191 \\
\hline $58 *$ & 8.201 & 8.444 & -0.243 & 8.269 & -0.068 \\
\hline 59 & 8.770 & 8.681 & 0.089 & 8.489 & 0.281 \\
\hline
\end{tabular}

* Test set molecules.

\subsection{Molecular Modeling and Alignment}

All computational studies were performed using SYBYL 8.1 molecular modeling software from Tripos, Inc., US [12]. 3D structures of all compounds were constructed using the Sketch Molecule module. Structural energy minimization was performed using the standard Tripos molecular mechanics force field and Gasteiger-Hückel charge [13]. The fragment that was used as the common structure is shown in Figure 1. The compound $\mathbf{9}$ was selected as a template molecule, which was one of the most active derivatives in the dataset. The aligned molecules of the training set are shown in Figure 2.

\subsection{CoMFA and CoMSIA Setup}

To calculate the CoMFA and CoMSIA fields, a 3D cubic lattice with grid spacing of $1 \AA$ and extending to $4 \AA$ units beyond the aligned molecules in all directions was created automatically by SYBYL [12]. In the CoMFA method, a $s p^{3}$ hybridized carbon atom with a charge of 1e served as the 
probe atom to calculate steric and electrostatic fields, in which their energy values were truncated at $30 \mathrm{kcal} / \mathrm{mol}$ [14]. The CoMSIA method, incorporating steric, electrostatic, hydrophobic, hydrogen bond donor and acceptor fields, was carried out using a probe atom with radius $1.0 \AA$ hydrophobic and hydrogen bond properties of +1 . The attenuation factor was set to the default value of 0.3 [15].

\subsection{Regression Analysis and Models Validation}

Partial Least Squares (PLS) was used to linearly correlate the CoMFA and CoMSIA fields to the $\mathrm{pIC}_{50}$ values. The performance of both the CoMFA and CoMSIA models was evaluated using the leave-one-out (LOO) method [16]. PLS was conjunct with the cross-validation option to determine the optimum number of components (ONC), which were then used in deriving the final CoMFA and CoMSIA model without cross-validation. The ONC was the number of components resulting in the highest cross-validated correlation coefficient $\left(r_{\mathrm{cv}}^{2}\right)$. After obtaining the optimum number of components, a PLS analysis was performed with no validation and column filtering 2.0 to generate the highest correlation coefficient $\left(r^{2}\right)$ [17-19].

\subsection{Predictive Correlation Co-Efficient $\left(r_{\text {pred }}^{2}\right)$}

The predictive abilities were determined from a test set of 13 compounds that were not included in the training set. These molecules were aligned to the template and their $\mathrm{pIC}_{50}$ values were predicted. The predictive correlation coefficient $\left(r^{2}\right.$ pred $)$, based on the molecules of test set, was calculated by the equation shown below.

$$
r_{\text {pred }}^{2}=(\mathrm{SD}-\mathrm{PRESS}) / \mathrm{SD}
$$

$\mathrm{SD}$ is the sum of the squared deviations between the inhibitory activities of the test set and mean activities of the training molecules and PRESS is the sum of squared deviations between predicted and actual activity values for each molecule in the test set [20-22].

\subsection{Molecular Docking}

To investigate the protein-ligand interactions, compound 9 was docked into the ATP-binding site of p38 $\alpha$ MAPK. The Surflex-Dock, using an empirical scoring function and a patented search engine to dock ligands into a protein's binding site, was applied to study molecular docking [12]. The crystal structure of $\mathrm{p} 38 \alpha$ MAPK was retrieved from the RCSB Protein Data Bank (PDB entry code: 3LHJ). The p38 $\alpha$ MAPK structure was utilized in subsequent docking experiments without energy minimization. The ligands were docked into the corresponding protein's binding site by an empirical scoring function and a patented search engine in Surflex-Dock [12]. All ligands and water molecules were removed and the polar hydrogen atoms were added. Protomol, an idealized representation of a ligand that makes every potential interaction with the binding site, was used to guide molecular docking. The establishment of protomol demonstrates three behaviors: (a) Automatic: Surflex-Dock finds the largest cavity in the receptor protein; (b) Ligand: a ligand in the same coordinate space as the receptor; (c) Residues: specified residues in the receptor [10]. In this paper, the automatic docking was 
applied. To visualize the binding mode between the protein and ligand, the MOLCAD (Molecular Computer Aided Design) program was employed. MOLCAD calculates and displays the surfaces of channels and cavities, as well as the separating surface between protein subunits [12]. The MOLCAD program provides a variety of properties and maps onto protein surfaces. In this paper, the cavity depth, electrostatic and lipophilic potential surfaces were established by MOLCAD. Other parameters were established by default in the software.

Figure 1. Fragment used as a common structure in the alignments.

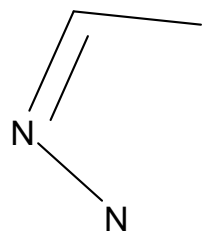

Figure 2. Alignment of the molecules used in the training set.

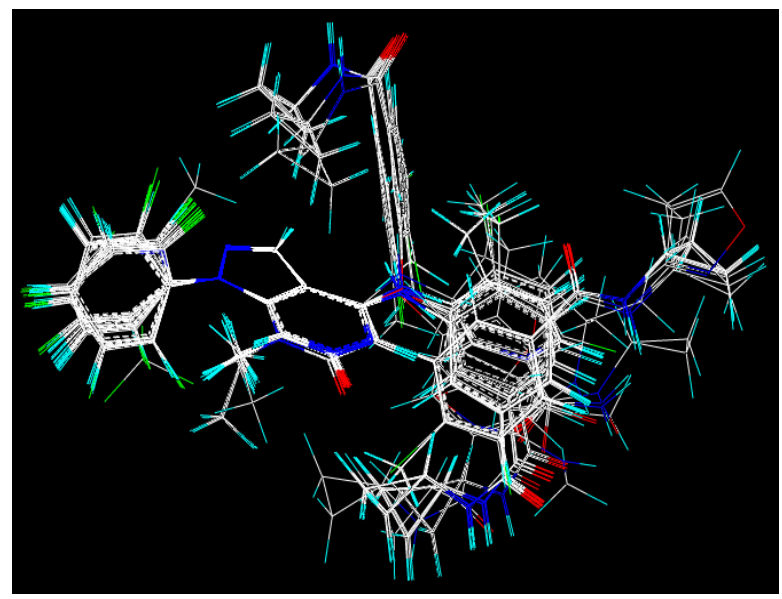

\section{Results and Discussion}

\subsection{CoMFA and CoMSIA Analysis}

The statistical parameters obtained from the CoMFA model are listed in Table 3. The CoMFA model, using 46 and 13 derivatives in the training and test sets, respectively, gave a cross-validated correlation coefficient $\left(r_{c v}^{2}\right)$ of $0.725(>0.6)$ with an optimized component of 6 , which suggests that the model should be a useful tool for predicting the $\mathrm{IC}_{50}$ values. An excellent non-cross-validated correlation coefficient $\left(r^{2}\right)$ of 0.961 with a low standard error estimate (SEE) of $0.178, F$ value of 160.943 and predictive correlation coefficient $\left(r_{\text {pred }}^{2}\right)$ of 0.953 was obtained. Contributions of steric and electrostatic fields were 0.534 and 0.466, respectively. The CoMSIA model, using steric, electrostatic, hydrophobic, hydrogen bond donor and hydrogen bond acceptor fields, gave a good cross-validated correlation coefficient $\left(r_{c v}^{2}\right)$ of $0.609(>0.6)$ with an optimized component of 6 . A high non-cross-validated correlation coefficient $\left(r^{2}\right)$ of 0.905 with a SEE of $0.279, F$ value of 61.672 and predictive correlation coefficient $\left(r_{\text {pred }}^{2}\right)$ of 0.929 was obtained. Contributions of steric, electrostatic, hydrophobic, hydrogen bond donor and hydrogen bond acceptor fields were $0.159,0.137,0.202,0.310$ and 0.192 , respectively. 
The experimental and predicted $\mathrm{pIC}_{50}$ values and residual values for the training set and test set compounds in CoMFA and CoMSIA are given in Table 2. The relationship between experimental and predicted $\mathrm{pIC}_{50}$ values of the training set and test set compounds in CoMFA and CoMSIA are illustrated in Figure 3(a),(b).

Table 3. The partial least squares (PLS) results obtained using the CoMFA and CoMSIA models.

\begin{tabular}{ccc}
\hline PLS Statistics & CoMFA & CoMSIA \\
\hline$r_{\mathrm{cv}}^{2}$ & 0.725 & 0.609 \\
$r^{2 \mathrm{~b}}$ & 0.961 & 0.905 \\
ONC $^{\mathrm{a}}$ & 6 & 6 \\
SEE $^{\mathrm{d}}$ & 0.178 & 0.279 \\
F value $^{\mathrm{e}}$ & 160.943 & 61.672 \\
$r_{\text {pred }}^{2}$ & 0.953 & 0.929 \\
Field contribution & & \\
Steric & 0.534 & 0.159 \\
Electrostatic & 0.466 & 0.137 \\
Hydrophobic & - & 0.202 \\
H-bond Donor & - & 0.310 \\
H-bond Acceptor & - & 0.192 \\
\hline
\end{tabular}

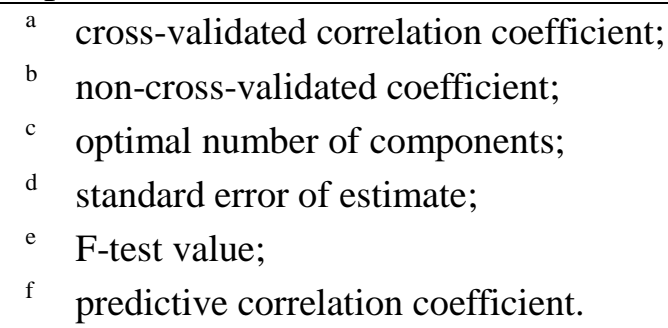

Figure 3. Graph of experimental versus predicted $\mathrm{pIC}_{50}$ of the training set and the test set using CoMFA (a) and CoMSIA (b).

(a)

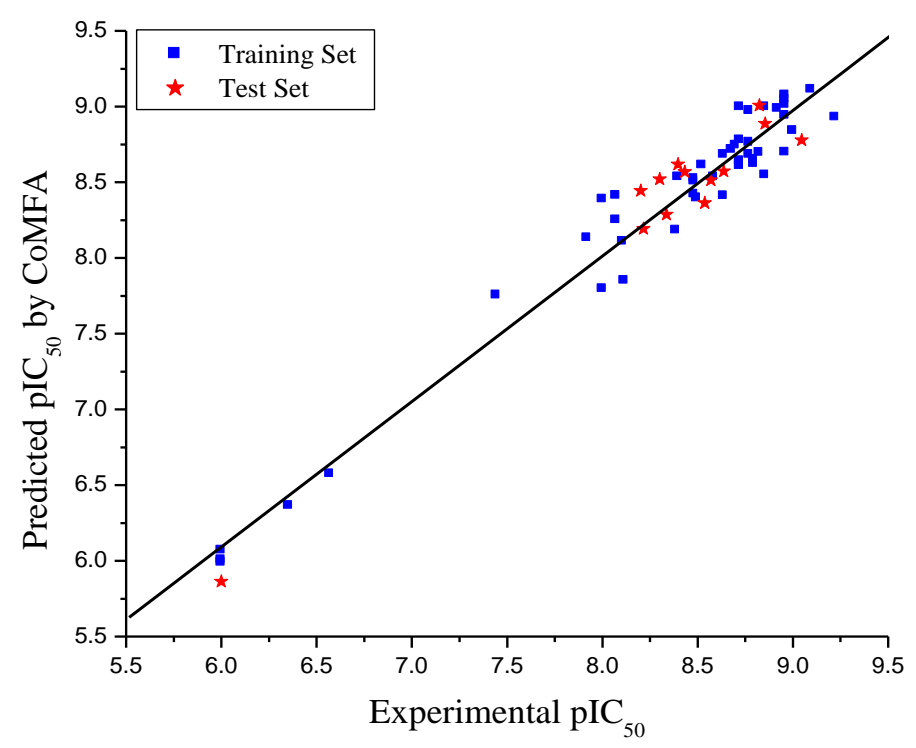


Figure 3. Cont.

(b)

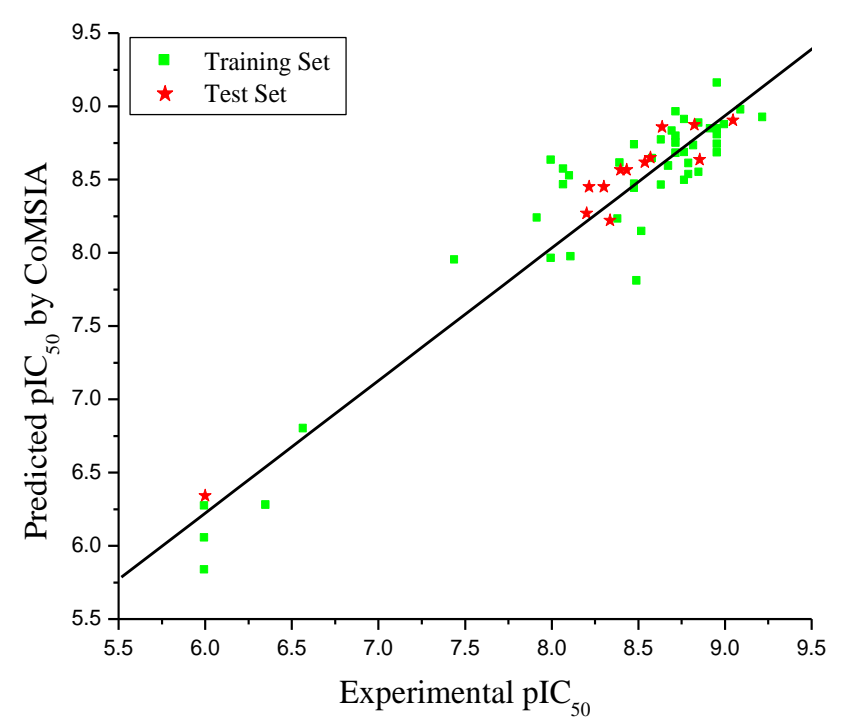

\subsection{Graphical Interpretation of CoMFA and CoMSIA}

One of the attractive features of the CoMFA and CoMSIA models is the visualization of the results as 3D coefficient contour maps. To visualize the information content of the derived 3D-QSAR model, CoMFA and CoMSIA contour maps were generated to rationalize the regions in 3D space around the molecules where changes in each field were predicted to increase or decrease the activity. The CoMFA steric and electrostatic contour maps that are shown in Figure 4 use compound 9 as a reference structure. In Figure 4(a), the green contours represent regions of high steric tolerance $(80 \%$ contribution) while the yellow contours represent regions of low steric bulk tolerance (20\% contribution). In Figure 4(b), the electrostatic field is indicated by blue (80\% contribution) and red (20\% contribution) contours, which reveal the regions where electron-donating group and electron-withdrawing group would be favorable, respectively.

As shown in Figure 4(a), the yellow contour near $\mathrm{R}_{1}$ position indicates that bulky groups would decrease the potency. Comparing compound 27 with $\mathbf{2 4}$, their activity discrepancies can be explained by this yellow contour. A huge green contour around the $\mathrm{R}_{3}$ and $\mathrm{R}_{4}$ position suggested that bulkier groups would be favored. Most of the derivatives possessed a relatively bulkier methyl substituent at the $R_{3}$ position, compounds 17-19, which had minor groups (e.g., H, F), showed significantly decreased activities. In Figure 4(b), the blue contour near the $R_{3}$ position indicates that electron-donating groups may increase the activity. This may explain why compounds 17-19, without an electron-donating substituent at this position, were the most inactive derivatives. A red contour near the $\mathrm{R}_{4}$ position demonstrated that electron-withdrawing groups would benefit the activity, compound 9 with an electron-withdrawing substituent (-F) at $\mathrm{R}_{4}$ showed significantly increased activity. Two blue contours around the $\mathrm{R}_{5}$ position strongly revealed that an electron-donating group would be favorable. Most of the compounds in the database possessed an electron-donating cyclopropyl substituent at $\mathrm{R}_{5}$, compounds 17-22 and 26 - without an electron-donating group at this position—showed significantly decreased activities. 
The CoMSIA steric, electrostatic, hydrophobic, hydrogen bond donor and acceptor field contour maps are shown in Figure 5 using compound $\mathbf{9}$ as a reference structure. The CoMSIA steric and electrostatic field contour maps were almost similar to the corresponding CoMFA contour maps.

The hydrophobic field contour map is shown in Figure 5(c), white (20\% contribution) and yellow (80\% contribution) contours highlight areas where hydrophilic and hydrophobic properties were favored. The yellow contour around the C-6 position revealed the extreme importance of the phenyl group at this position; replacing it with a hydrophilic group may result in decreased activity. Two white contours near $\mathrm{R}_{4}$ and N-15 positions indicated that hydrophilic substituents may be favored.

The hydrogen bond donor field contour map is illustrated in Figure 5(d), the cyan $(80 \%$ contribution) and purple (20\% contribution) contours indicate favorable and unfavorable hydrogen bond donor groups. The purple contour near the $C^{\prime}-2$ position of the phenyl group in $R_{2}$ indicates that a hydrogen bond donor would be unfavorable. In general, compounds with a hydrogen bond acceptor substituent (e.g., -F) at the $\mathrm{C}^{\prime}-2$ position showed better activities than those without a hydrogen bond acceptor group. The carbonyl group in the $\mathrm{C}-14$ position was surrounded by a huge purple contour, suggesting it may serve as a hydrogen bond acceptor and that removing it may result in decreased potency.

The hydrogen bond acceptor field contour map is depicted in Figure 5(e), the purple $(80 \%$ contribution) and red (20\% contribution) contours favorable and unfavorable positions for hydrogen bond acceptors. The purple contour near the carbonyl group in the $\mathrm{C}-14$ position revealed a hydrogen bond acceptor substituent at this position would benefit the activity. A red contour near N-15 position revealed the importance of the hydrogen bond donor - $\mathrm{NH}$ group.

Figure 4. CoMFA Std* coeff contour maps illustrating steric, electrostatic fields in combination with compound 9. (a) Steric fields: green contours (80\% contribution) indicate regions where bulky groups increase activity, while yellow contours $(20 \%$ contribution) indicate regions where bulky groups decrease activity, and (b) Electrostatic fields: blue contours ( $80 \%$ contribution) indicate regions where electron-donating groups increase activity, while red contours (20\% contribution) indicate regions where electron-withdrawing groups increase activity.

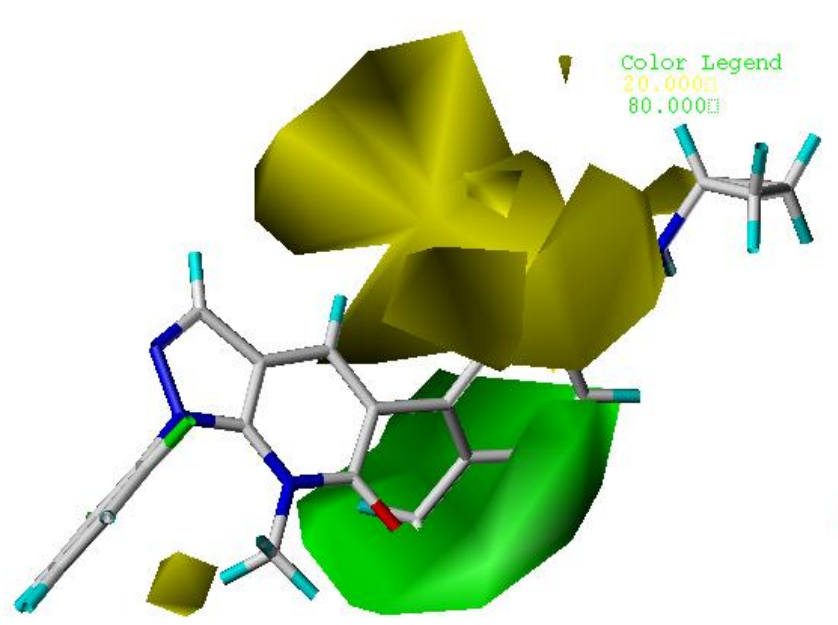

(a)

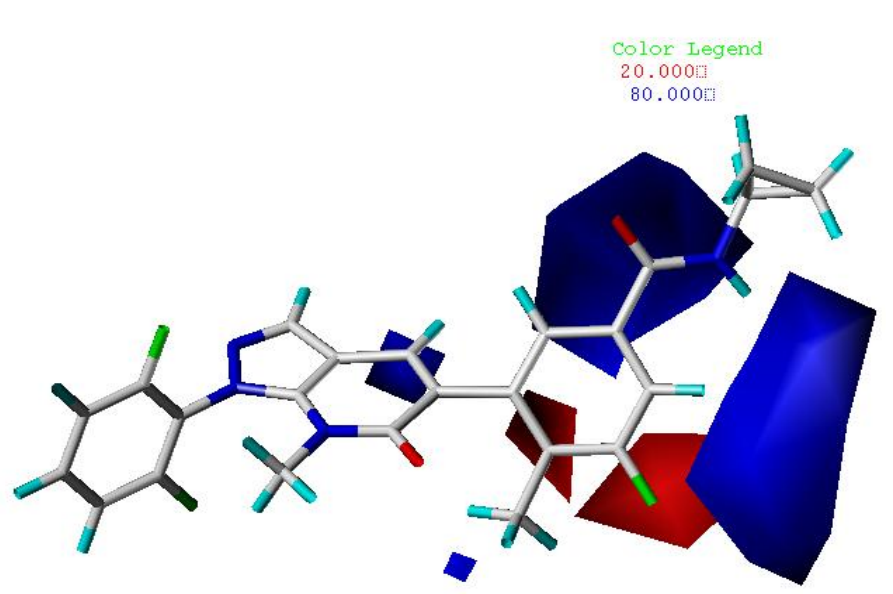

(b) 
Figure 5. Std* coeff contour maps of CoMSIA illustrating steric, electrostatic, hydrophobic, hydrogen bond donor and acceptor fields in combination with compound 9. (a) Steric contour map. Green contours refer to sterically favored regions while yellow contours refer to sterically disfavored regions. (b) Electrostatic contour map. Blue contours refer to regions where electron-donating groups are favored; red contours indicate regions where electron-withdrawing groups are favored. (c) Hydrophobic contour map. White contours (80\% contribution) refer to regions where hydrophilic substituents are favored; yellow contours (20\% contribution) indicate regions where hydrophobic substituents are favored. (d) Hydrogen bond donor contour map. The cyan (80\% contribution) and purple ( $20 \%$ contribution) contours indicate favorable and unfavorable hydrogen bond donor groups. (e) Hydrogen bond acceptor contour map. The purple contours (80\% contribution) for hydrogen bond acceptor groups increase activity, red contours (20\% contribution) indicate the disfavored region.

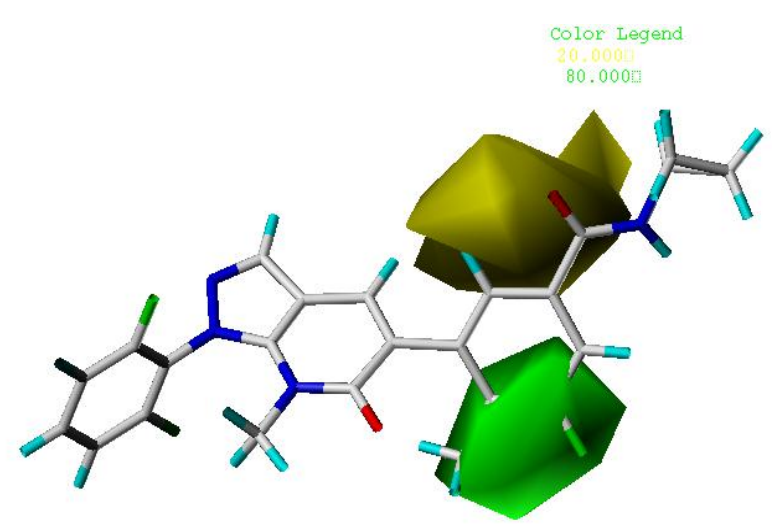

(a)

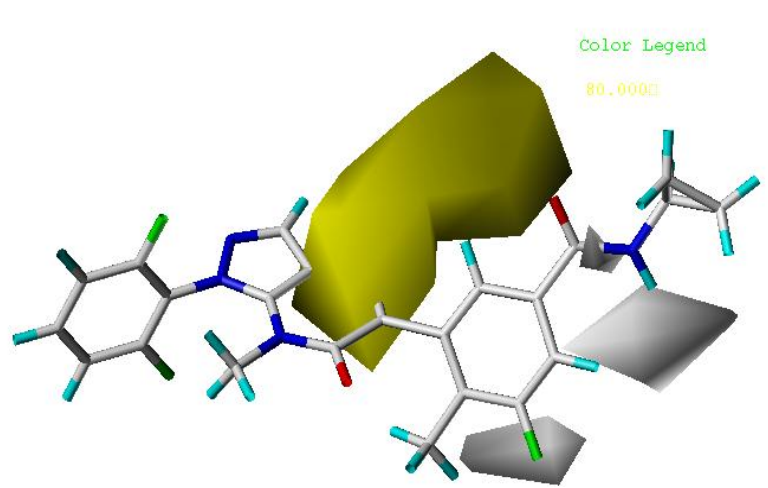

(c)

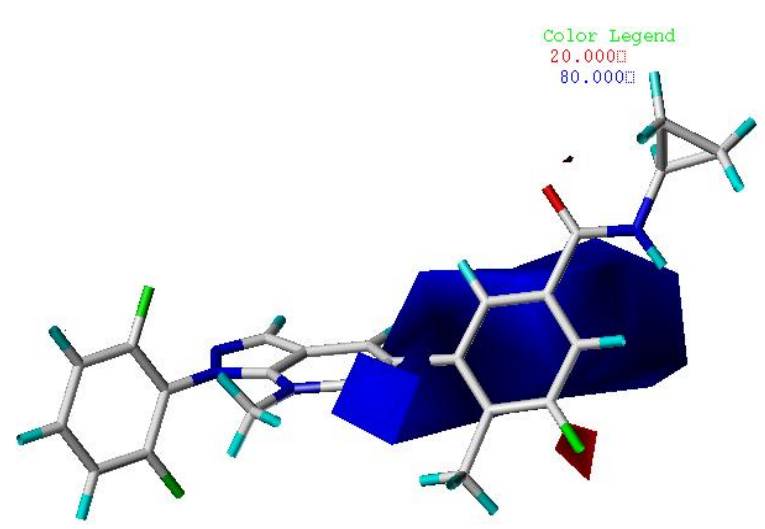

(b)

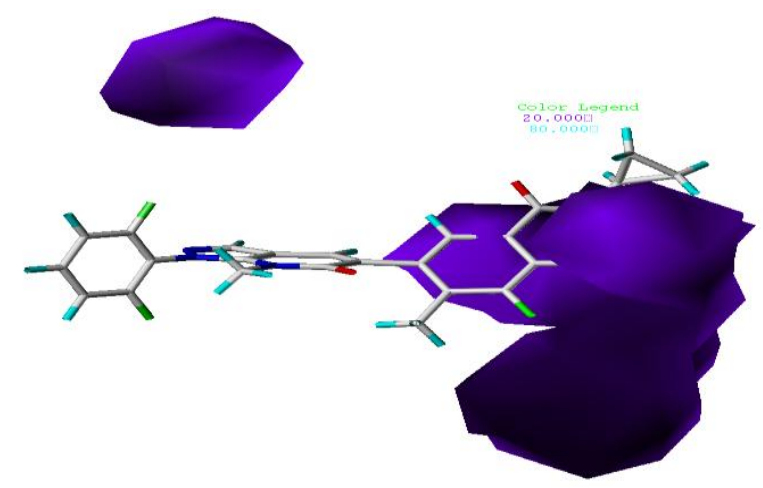

(d)

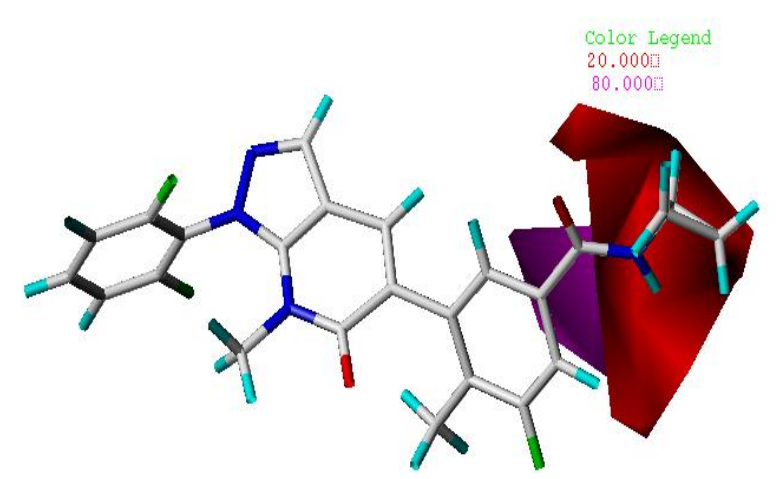

(e) 


\subsection{Docking Analysis}

To explore the interaction mechanism between these inhibitors and the receptor, compound 9 was selected for more detailed analysis. The MOLCAD Robbin surfaces structure of the ATP pocket of the p38 $\alpha$ MAP within the compound 9 is shown in Figure 6. The $-\mathrm{F}$ at $\mathrm{C}^{\prime}-2$ position acted as a hydrogen bond acceptor and formed a $\mathrm{H}$-bond with the $-\mathrm{NH}$ of the Met 109 residue, the carbonyl group at C-14 position also acted as a hydrogen bond acceptor by forming a H-bond with the -NH of the ASP168. The observations obtained from Figure 6 are in agreement with that of CoMSIA hydrogen bond donor and acceptor contour maps.

Figure 6. MOLCAD Robbin surfaces structure of selected compound 9 in complex with the ATP pocket of P38 $\alpha$ MAPK (PDB code: 3LHJ). Key residues and hydrogen bonds are labeled. The alpha helices are shown as yellow helices or cylinders, while beta sheets are shown as blue arrows and the loop regions as red tubes.

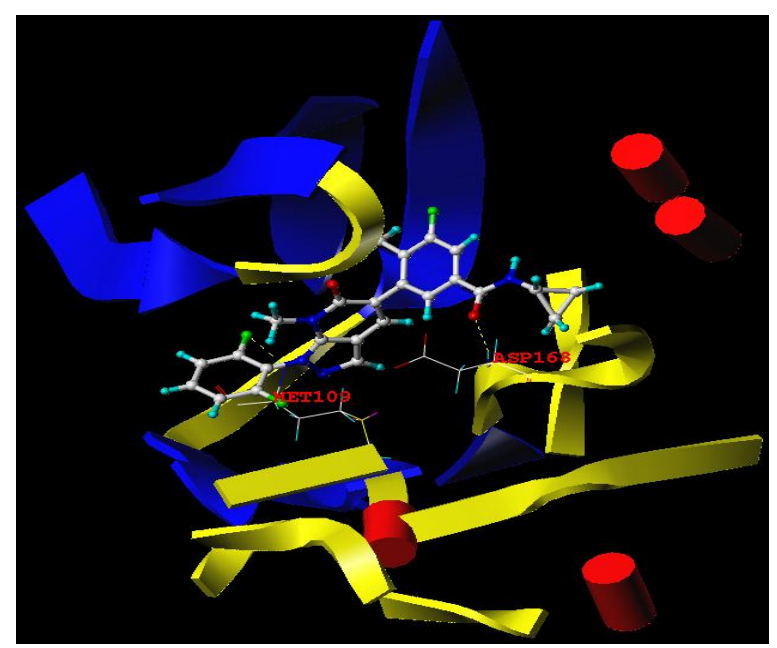

The MOLCAD Robbin and Multi-Channel surfaces structure of the ATP-binding site of the p38 $\alpha$ MAP were also developed and displayed with cavity depth, electrostatic potential as well as lipophilic potential to explore the ligand-receptor interactions, furthermore, to examine the $3 \mathrm{D}$ contour maps obtained by CoMFA and CoMSIA.

Figure 7(a) depicts the MOLCAD cavity depth potential surface of the ATP pocket within compound 9, the cavity depth color ramp ranges from blue (low depth values = outside of the pocket) to light red (high depth values = cavities deep inside the pocket). As shown in Figure 7(a), the phenyl group of $\mathrm{R}_{2}$ position was in the relative lower depth, while the other parts of the compound $\mathbf{9}$ were anchored deep inside the ATP pocket.

Figure 7(b) demonstrates the MOLCAD electrostatic potential surface of the ATP-binding region, the color ramp for EP ranges from red (most positive) to purple (most negative). In Figure 7(b), the $\mathrm{R}_{3}$ position was found in a yellow area, which indicated that electron-withdrawing properties were essential for potency; the $\mathrm{R}_{5}$ position was in a blue area, which suggested that electron-donating properties were crucial for activity. The observations obtained from this electrostatic potential surface were satisfied according to the corresponding CoMFA and CoMSIA electrostatic contour maps. 
Figure 7(c) shows the MOLCAD lipophilic potential surface of the ATP pocket, the color ramp for LP ranges from brown (highest lipophilic area of the surface) to blue (highest hydrophilic area). The phenyl group at $\mathrm{C}-5$ position was in a brown area, which revealed the importance of hydrophobic properties for this position; the N-15 position was in a white area, which indicated the significance of hydrophilic properties for this position. These observations are in agreement with that obtained from the CoMSIA hydrophobic contour map.

Figure 7. The MOLCAD Robbin and Multi-Channel surfaces structure displayed with cavity depth (a), electrostatic (b) and lipophilic (c) potential surfaces of the ATP pocket of p38 $\alpha$ MAPK within the compound 9. The cavity depth color ramp ranges from blue (low depth values $=$ outside of the pocket) to light red (high depth values = cavities deep inside the pocket). The color ramp for EP ranges from red (most positive) to purple (most negative). The color ramp for LP ranges from brown (highest lipophilic area of the surface) to blue (highest hydrophilic area).

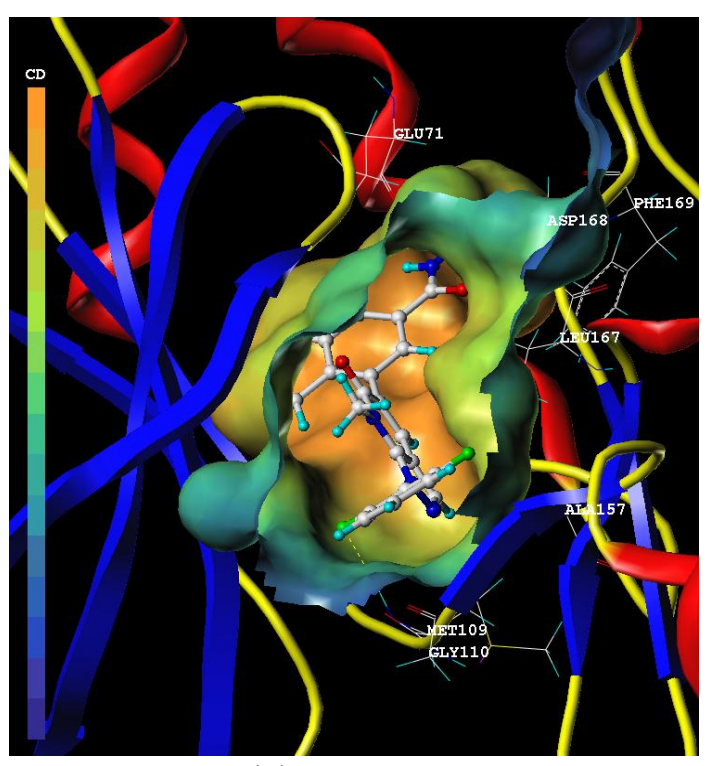

(a)

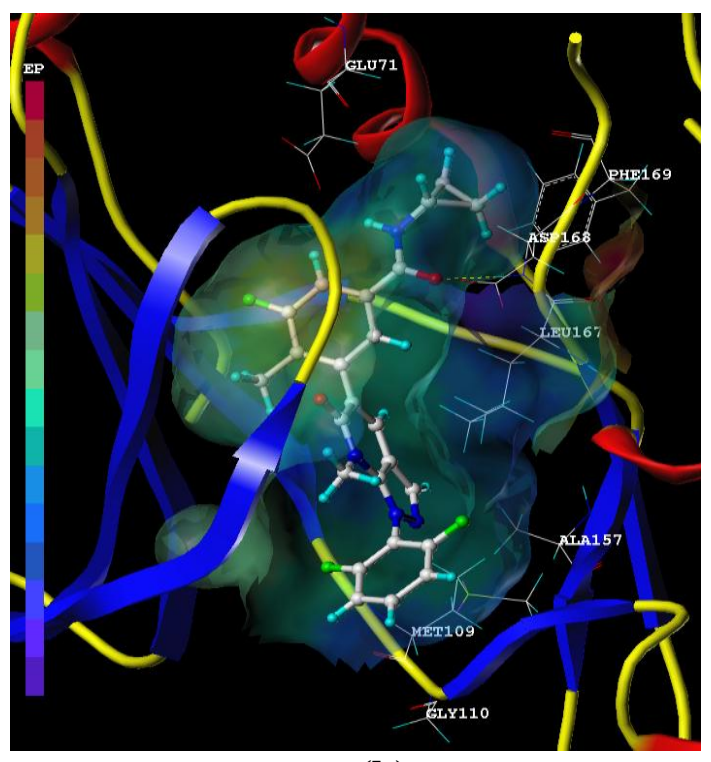

(b)

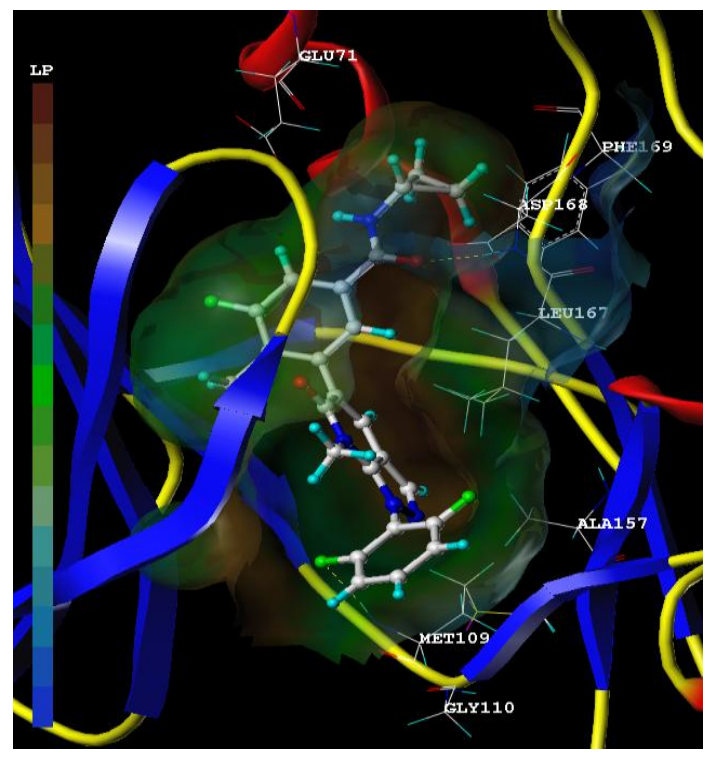

(c) 


\subsection{Summary of the Structure-Activity Relationship}

The structure-activity relationship revealed by 3D-QSAR and molecular docking studies is illustrated in Figure 8. In detail, the minor substituent in the $\mathrm{R}_{1}$ position would be favored; the bulky, electron-donating groups in $\mathrm{R}_{3}$ position would increase the activity; the bulky, electron-withdrawing, hydrophilic groups in $\mathrm{R}_{4}$ position would benefit the potency; the minor, electron-donating substituent in $\mathrm{R}_{5}$ position would be favorable; the $-\mathrm{F}$ at the $\mathrm{C}^{\prime}-2$ position and the carbonyl group at $\mathrm{C}-14$ position are crucial for binding to the ATP pocket.

Figure 8. Summary of structure-activity relationship revealed by 3D-QSAR and docking.

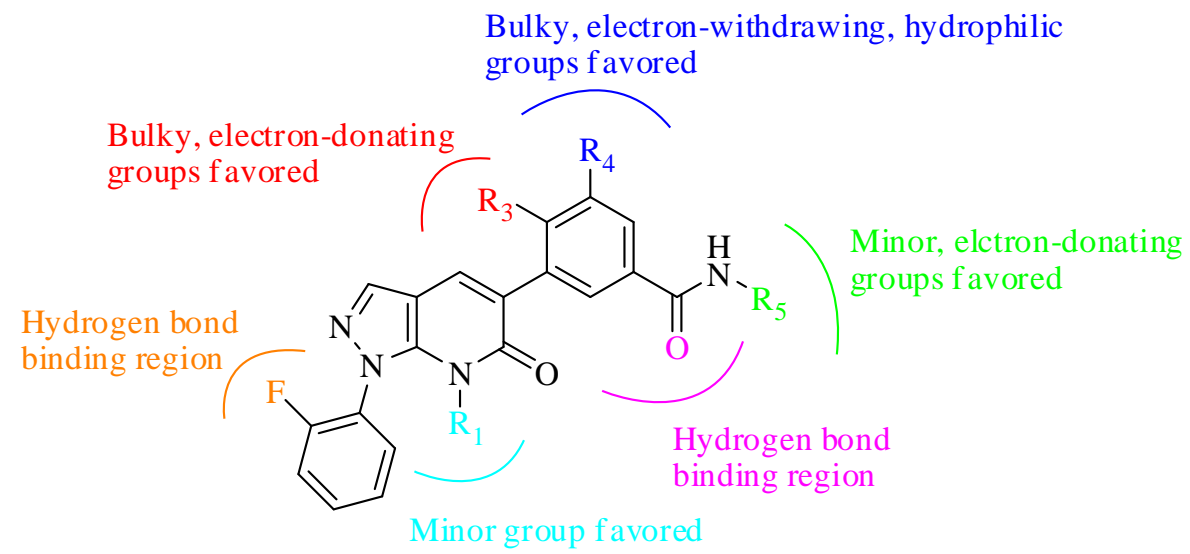

\subsection{Design for New Inhibitors}

Based on the structure-activity relationship revealed by this study, we have designed a series of novel inhibitors, these molecules were aligned to the database and their activities were predicted by the CoMFA and CoMSIA models previously established. The chemical structures and predicted $\mathrm{pIC}_{50}$ values of these compounds are shown in Table 4 . The predicted pIC $_{50}$ values of these compounds versus that of the most active compound 9 are illustrated in Figure 9. Most of the designed molecules showed better $\mathrm{pIC}_{50}$ values than compound $\mathbf{9}$, which validated the structure-activity relationship obtained in this study.

Figure 9. Graph of the predicted $\mathrm{pIC}_{50}$ values of the designed inhibitors using CoMFA and CoMSIA.

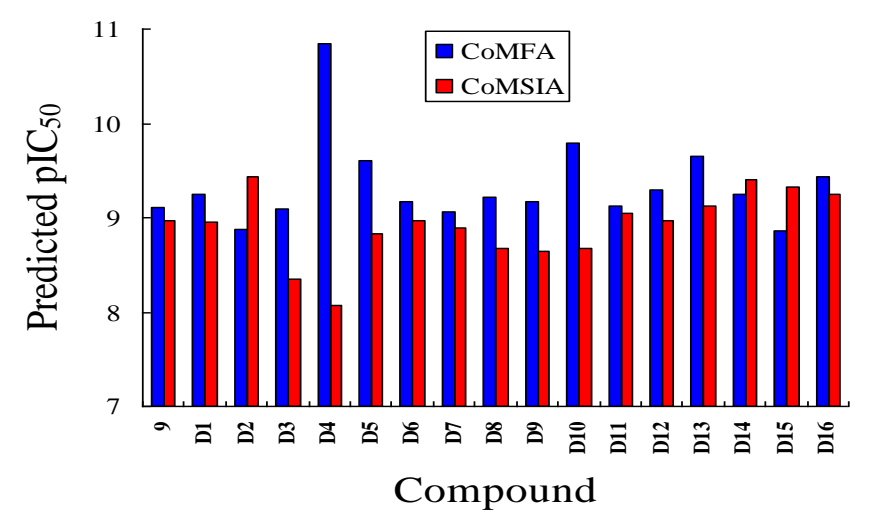


Table 4. Chemical structures of the newly designed inhibitors and their $\mathrm{pIC}_{50}$ values.

\begin{tabular}{|c|c|c|c|c|c|c|}
\hline \multirow{2}{*}{ No. } & \multicolumn{4}{|c|}{ Substituent } & \multicolumn{2}{|c|}{ Predicted pIC 50} \\
\hline & $\mathbf{R}_{1}$ & $\mathbf{R}_{\mathbf{3}}$ & $\mathbf{R}_{\mathbf{4}}$ & $\mathbf{R}_{5}$ & CoMFA & CoMSIA \\
\hline D1 & $\mathrm{Me}$ & $\mathrm{CH}_{2} \mathrm{OOCCH}_{3}$ & $\mathrm{COOH}$ & $\mathrm{Et}$ & 9.253 & 8.961 \\
\hline D2 & $\mathrm{Me}$ & $\mathrm{CH}_{2} \mathrm{OOCCH}_{3}$ & $\mathrm{CONH}_{2}$ & Et & 8.881 & 9.438 \\
\hline D3 & $\mathrm{Me}$ & $\mathrm{C}\left(\mathrm{CH}_{3}\right)_{3}$ & $\mathrm{COOH}$ & $\mathrm{Et}$ & 9.093 & 8.343 \\
\hline D4 & $\mathrm{Me}$ & $\mathrm{OC}\left(\mathrm{CH}_{3}\right)_{3}$ & $\mathrm{SO}_{3} \mathrm{H}$ & Et & 10.845 & 8.064 \\
\hline D5 & $\mathrm{Me}$ & $\mathrm{CH}_{2} \mathrm{OOCCH}_{3}$ & $\mathrm{SO}_{3} \mathrm{H}$ & $\mathrm{Et}$ & 9.604 & 8.835 \\
\hline D6 & $\mathrm{Me}$ & $\mathrm{C}\left(\mathrm{CH}_{3}\right)_{3}$ & $\mathrm{SO}_{3} \mathrm{H}$ & $\mathrm{Et}$ & 9.171 & 8.970 \\
\hline D7 & $\mathrm{H}$ & $\mathrm{C}\left(\mathrm{CH}_{3}\right)_{3}$ & $\mathrm{COOH}$ & $\mathrm{Me}$ & 9.056 & 8.885 \\
\hline D8 & $\mathrm{Me}$ & $\mathrm{OC}\left(\mathrm{CH}_{3}\right)_{3}$ & $\mathrm{NO}_{2}$ & $\mathrm{Et}$ & 9.210 & 8.667 \\
\hline D9 & $\mathrm{Me}$ & $\mathrm{OCH}\left(\mathrm{CH}_{3}\right)_{2}$ & $\mathrm{NO}_{2}$ & Et & 9.168 & 8.638 \\
\hline D10 & $\mathrm{Me}$ & $\mathrm{CH}_{2} \mathrm{OOCCH}_{3}$ & $\mathrm{NO}_{2}$ & Et & 9.792 & 8.668 \\
\hline D11 & $\mathrm{Me}$ & $\mathrm{OC}\left(\mathrm{CH}_{3}\right)_{3}$ & $\mathrm{CN}$ & $\mathrm{Et}$ & 9.129 & 9.052 \\
\hline D12 & $\mathrm{Me}$ & $\mathrm{OCH}\left(\mathrm{CH}_{3}\right)_{2}$ & $\mathrm{CN}$ & Et & 9.288 & 8.966 \\
\hline D13 & $\mathrm{Me}$ & $\mathrm{C}\left(\mathrm{CH}_{3}\right)_{3}$ & $\mathrm{CN}$ & $\mathrm{Et}$ & 9.651 & 9.121 \\
\hline D14 & $\mathrm{H}$ & $\mathrm{C}\left(\mathrm{CH}_{3}\right)_{3}$ & $\mathrm{CF}_{3}$ & Et & 9.245 & 9.408 \\
\hline D15 & $\mathrm{H}$ & $\mathrm{OC}\left(\mathrm{CH}_{3}\right)_{3}$ & $\mathrm{CF}_{3}$ & $\mathrm{Et}$ & 8.857 & 9.328 \\
\hline D16 & $\mathrm{Me}$ & $\mathrm{C}\left(\mathrm{CH}_{3}\right)_{3}$ & $\mathrm{CF}_{3}$ & $\mathrm{Et}$ & 9.430 & 9.250 \\
\hline
\end{tabular}

\section{Conclusion}

In conclusion, the 3D-QSAR and docking models established in our present study are quite reliable to efficiently guide further modification of the fused pyrazole derivatives for obtaining better inhibitors. Both the CoMFA and CoMSIA models provided the significant correlations of biological activities with steric, electrostatic, hydrophobic, hydrogen bond donor and acceptor fields. In comparison to CoMSIA, the CoMFA method was found to afford a slightly better predictability. The structure-activity relationships revealed by $3 \mathrm{D}-\mathrm{QSAR}$ and docking were validated by newly designed derivatives. The results served as a useful guideline for developing novel p38 $\alpha$ MAPK inhibitors.

\section{Acknowledgements}

The authors were thankful to the Natural Science Foundation of Guangdong Province (No. 9151063201000053) and the Fundamental Research Funds for the Central Universities (No. 21610405), China for financial support. 


\section{References}

1. Pettus, L.H.; Wurz, R.P.; Xu, S.; Herberich, B.; Henkle, B.; Liu, Q.; McBride, H.J.; Mu, S.; Plant, M.H.; Saris, C.J.M.; Sherman, L.; Wong, L.M.; Chmait, S.; Lee, M.R.; Mohr, C.; Hsieh, F.; Tasker, A.S. Discovery and evaluation of 7-alkyl-1,5-bis-aryl-pyrazolopyridinones as highly potent, selective, and orally efficacious inhibitors of $\mathrm{p} 38 \alpha$ mitogen-activated protein kinase. J. Med. Chem. 2010, 53, 2973-2985.

2. Wurz, R.P.; Pettus, L.H.; Henkle, B.; Sherman, L.; Plant, M.; Miner, K.; McBride, H.J.; Wong, L.M.; Saris, C.J.M.; Lee, M.R.; Chmait, S.; Mohr, C.; Hsieh, F.; Tasker, A.S. Part2: Structure-activity relationship (SAR) investigations of fused pyrazoles as potent, selective and orally available inhibitors of p38 $\alpha$ mitogen-activated protein kinase. Bioorg. Med. Chem. Lett. 2010, 20, 1680-1684.

3. Wurz, R.P.; Pettus, L.H.; Xu, S.; Henkle, B.; Sherman, L.; Plant, M.; Miner, K.; McBride, H.; Wong, L.M.; Saris, C.J.M.; Lee, M.R.; Chmait, S.; Mohr, C.; Hsieh, F.; Tasker, A.S. Part 1: Structure-activity relationship (SAR) investigations of fused pyrazoles as potent, selective and orally available inhibitors of p38a mitogen-activated protein kinase. Bioorg. Med. Chem. Lett. 2009, 19, 4724-4728.

4. Hynes, J., Jr.; Dyckman, A.J.; Lin, S.; Wrobleski, S.T.; Wu, H.; Gillooly, K.M.; Kanner, S.B.; Lonial, H.; Loo, D.; McIntyre, K.W.; Pitt, S.; Shen, D.R.; Shuster, D.J.; Yang, S.; Zhang, R.; Behnia, K.; Zhang, H.; Marathe, P.H.; Doweyko, A.M.; Tokarski, J.S.; Sack, J.S.; Pokross, M.; Kiefer, S.E.; Newitt, J.A.; Barrish, J.C.; Dodd, J.; Schieven, G.L.; Leftheris, K. Design, synthesis, and anti-inflammatory properties of orally active 4-(phenylamino)-pyrrolo[2,1-f][1,2,4]triazine p38a mitogen-activated protein kinase inhibitors. J. Med. Chem. 2008, 51, 4-16.

5. Pettus, L.H.; Xu, S.; Cao, G.-Q.; Chakrabarti, P.P.; Rzasa, R.M.; Sham, K.; Wurz, R.P.; Zhang, D.; Middleton, S.; Henkle, B.; Plant, M.H.; Saris, C.J.M.; Sherman, L.; Wong, L.M.; Powers, D.A.; Tudor, Y.; Yu, V.; Lee, M.R.; Syed, R.; Hsieh, F.; Tasker, A.S. 3-Amino-7-phthalazinylbenzoisoxazoles as a novel class of potent, selective, and orally available inhibitors of p38 a mitogen-activated protein kinase. J. Med. Chem. 2008, 51, 6280-6292.

6. Laufer, S.A.; Hauser, D.R.J.; Domeyer, D.M.; Kinkel, K.; Liedtke, A.J. Design, synthesis, and biological evaluation of novel tri- and tetrasubstituted imidazoles as highly potent and specific ATP-mimetic inhibitors of p38 $\alpha$ mitogen-activated protein kinase: Focus on optimized interactions with the enzyme's surface-exposed front region. J. Med. Chem. 2008, 51, 4122-4149.

7. Koch, P.; Jahns, H.; Schattel, V.; Goettert, M.; Laufer, S. Pyridinylquinoxalines and pyridinylpyridopyrazines as lead compounds for novel p38 $\alpha$ mitogen-activated protein kinase inhibitors. J. Med. Chem. 2010, 53, 1128-1137.

8. Thaher, B.A.; Koch, P.; Schattel, V.; Laufer, S. Role of the hydrogen bonding heteroatom-lys53 interaction between the p38 $\alpha$ mitogen-activated protein (MAP) kinase and pyridinyl-substituted 5-membered heterocyclic ring inhibitors. J. Med. Chem. 2009, 52, 2613-2617.

9. Lumeras, W.; Caturla, F.; Vidal, L; Esteve, C.; Balague, C.; Orellana, A.; Dominguez, M.; Roca, R.; Huerta, J.M.; Godessart, N.; Vidal, B. Design, synthesis, and structure-activity relationship of aminopyridine N-oxides, a novel scaffold for the potent and selective inhibition of p38 $\alpha$ mitogen-activated protein kinase. J. Med. Chem. 2009, 52, 5531-5545. 
10. Hauser, D.R.J.; Scior, T.; Domeyer, D.M.; Kammerer, B.; Laufer, S.A. Synthesis, biological testing, and binding mode prediction of 6,9-diarylpurin-8-ones as p38 $\alpha$ MAP kinase inhibitors. $J$. Med. Chem. 2007, 50, 2060-2066.

11. Peifer, C.; Kinkel, K.; Abadleh, M.; Schollmeyer, D.; Laufer, S. From five- to six- membered rings: 3,4-diarylquinolinone as lead for novel p38 $\alpha$ MAP kinase inhibitors. J. Med. Chem. 2007, $50,1213-1221$.

12. Sybyl 8.1; Tripos Inc.: St. Louis, MO, USA, 2008. Available online: http://www.tripos.com (accessed on 11 September 2010).

13. Yang, Z.; Sun, P. 3D-QSAR study of potent inhibitors of phosphodiesterase-4 using a CoMFA approach. Int. J. Mol. Sci. 2007, 9, 714-722.

14. Sun, J.; Cai, S.; Yan, N.; Mei, H. Docking and 3D-QSAR studies of influenza neuraminidase inhibitors using three-dimensional holographic vector of atomic interaction field analysis. Eur. $J$. Med. Chem. 2010, 45, 1008-1014.

15. Zhang, N.; Zhong, R. Docking and 3D-QSAR studies of 7-hydroxycoumarin derivatives as CK2 inhibitors. Eur. J. Med. Chem. 2010, 45, 292-297.

16. Zhou, Z.; Wang, Y.; Bryant, S.H. QSAR models for predicting cathepsin B inhibition by small molecules continuous and binary QSAR model to classify cathepsin B inhibition activities of small molecules. J. Mol. Grap. Model. 2010, 28, 714-727.

17. Sivan, S.K.; Manga, V. Molecular docking and 3D-QSAR studies on triazolinone and pyridazinone, non-nucleoside inhibitor of HIV-1 reverse transcriptase. J. Mol. Model. 2010, 16, 1169-1178.

18. Song, Q.-L.; Sun, P.-H.; Chen, W.-M. Exploring 3D-QSAR for ketolide derivatives as antibacterial agents using CoMFA and CoMSIA. Lett. Drug Des. Discov. 2010, 7, 149-159.

19. Morshed, M.N.; Muddassar, M.; Pasha, F.A.; Cho, S.J. Pharmacophore identification and validation study of CK2 inhibitors using CoMFA/CoMSIA. Chem. Biol. Drug Des. 2009, 74, $148-158$.

20. Zeng, H.; Cao, R.; Zhang, H. Combined 3D-QSAR modeling and molecular docking study on quinoline derivatives as inhibitors of P-selectin. Chem. Biol. Drug Des. 2009, 74, 596-610.

21. Roy, K.; Pau, S. Docking and 3D-QSAR studies of acetohydroxy acid synthase inhibitor sulfonylurea derivatives. J. Mol. Model. 2010, 16, 951-964.

22. Srivastava, V.; Gupta, S.P.; Siddiqi, M.I.; Mishra, B.N. 3D-QSAR studies on quinazoline antifolate thymidylate synthase inhibitors by CoMFA and CoMSIA models. Eur. J. Med. Chem. 2010, 45, 1560-1571.

(C) 2010 by the authors; licensee MDPI, Basel, Switzerland. This article is an open access article distributed under the terms and conditions of the Creative Commons Attribution license (http://creativecommons.org/licenses/by/3.0/). 